\title{
Влияние температуры отжига на электрически активные центры в кремнии, имплантированном ионами германия
}

\author{
(C) Н.А. Соболев ${ }^{1}$, О.В. Александров ${ }^{2}$, В.И. Сахаров ${ }^{1}$, И.Т. Серенков ${ }^{1}$, Е.И. Шек ${ }^{1}$, \\ A.E. Калядин ${ }^{1}$, Е.О. Паршин ${ }^{3}$, Н.С. Мелесов ${ }^{3}$ \\ ${ }^{1}$ Физико-технический институт им. А.Ф. Иоффе Российской академии наук, \\ 194021 Санкт-Петербург, Россия \\ ${ }^{2}$ Санкт-Петербургский государственный электротехнический университет „ЛЭТИ“ им. В.И. Ульянова (Ленина) \\ (СПбГЭТУ), \\ 197376 Санкт-Петербург, Россия \\ ${ }^{3}$ Ярославский филиал Физико-технологического института Российской академии наук, \\ 150007 Ярославль, Россия \\ E-mail: nick@sobolev.ioffe.rssi.ru
}

(Получена 28 августа 2018 г. Принята к печати 10 сентября 2018 г.)

\begin{abstract}
Установлено, что имплантация выращенного методом Чохральского кремния $p$-типа проводимости ионами германия с энергией $1 \mathrm{MэВ} \mathrm{и} \mathrm{дозой} 2.5 \cdot 10^{14} \mathrm{~cm}^{-2}$ не приводит к аморфизации монокристаллического кремния. При последующем высокотемпературном отжиге имплантированных образцов происходит трансформация электрически активных акцепторных центров. Их концентрация и пространственное распределение зависят от температуры отжига. Обсуждаются возможные факторы, определяющие процесс их формирования.
\end{abstract}

DOI: 10.21883/FTP.2019.02.47092.8977

В последнее время проводятся обширные исследования по созданию светоизлучающих структур (СИС) на основе кремния [1]. Наиболее перспективными для практического применения в кремниевой оптоэлектронике являются СИС с люминесценцией редкоземельных (Р3) ионов (например, эрбия $\mathrm{Er}^{3+}$ ) и так называемой дислокационной люминесценцией [2]. Также предпринимаются попытки использовать люминесценцию $\{113\}$ дефектов [3]. Ионная имплантация позволяет создавать СИС с указанными видами люминесценции и в то же время она относительно легко может быть встроена в микро- и нанотехнологию создания интегральных схем на основе кремния. Формирование СИС с помощью имплантационной технологии включает в себя две стадии: имплантацию ионов и последующий отжиг. Имплантация ионов с заданными энергиями и дозами обеспечивает введение примесей, которые непосредственно участвуют в создании светоизлучающих центров (для создания центров внутрицентровой люминесценции P3 ионов соимплантируются ионы Р3 элементов и примесей-активаторов) или способствуют формированию протяженных дефектов (как это имеет место при создании центров дислокационной люминесценции или люминесценции $\{113\}$ дефектов). Послеимплантационный отжиг обеспечивает отжиг введенных при имплантации центров безызлучательной рекомбинации, формирование самих люминесцентных центров и электрически активных центров, которые позволяют изготовить структуры светодиодиодов (СД). В настоящее время достаточно подробно исследованы процессы имплантации и формирования люминесцентных центров. Работ же, в которых исследуются процессы формирования электрически активных центров, существенно меньше.
Применительно к СД с дислокационной люминесценцией исследовано влияние условий отжига на электрически активные центры в кремнии, имплантированном ионами $\mathrm{O}, \mathrm{Er}, \mathrm{Ho}$, Dу и $\mathrm{Yb}$ [4-9]. Представляется, что имплантация ионов изовалентной примеси Ge, с атомным радиусом, значительно превышающим размеры атомов $\mathrm{Si}$, также перспективна для создания СД с дислокационной люминесценцией. Образование электрически активных центров в образцах после имплантации и облучения быстрыми частицами и их трансформация в процессе низкотемпературного отжига исследовалась достаточно подробно [10]. Насколько нам известно, исследование процессов отжига имплантированных структур $\mathrm{Si}: \mathrm{Ge}$ при высоких температурах не проводилось. Цель настоящей работы заключалась в изучении влияния условий отжига на электрически активные центры в кремнии, имплантированном ионами германия.

В качестве подложек использовались пластины кремния, выращенного методом Чохральского, p-типа проводимости (p-Cz-Si) толщиной 300 мкм, диаметром 76 мм, легированные бором с удельным сопротивлением 12 Ом · см (марки КДБ-12). Ионы Ge имплантирова-

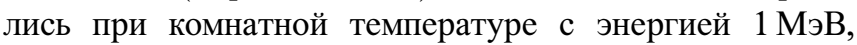
дозой $2.5 \cdot 10^{14} \mathrm{~cm}^{-2}$ при плотности тока $\leq 4 \mathrm{HA} / \mathrm{cm}^{2}$. Длина проецированного пробега ионов $\left(R_{P}\right)$ равнялась 730 нм [11]. Имплантация проводилась на ускорителе High Voltage Engineering Europe (Голландия). Пучок ионов направлялся под углом $7^{\circ}$ от нормали к имплантируемой поверхности, чтобы избежать эффекта каналирования. Дефектная структура имплантированных слоев исследовалась с помощью метода обратного резерфордовского рассеяния (RBS) протонов с энергией 227 кэВ. Кремниевый детектор с энергетическим 

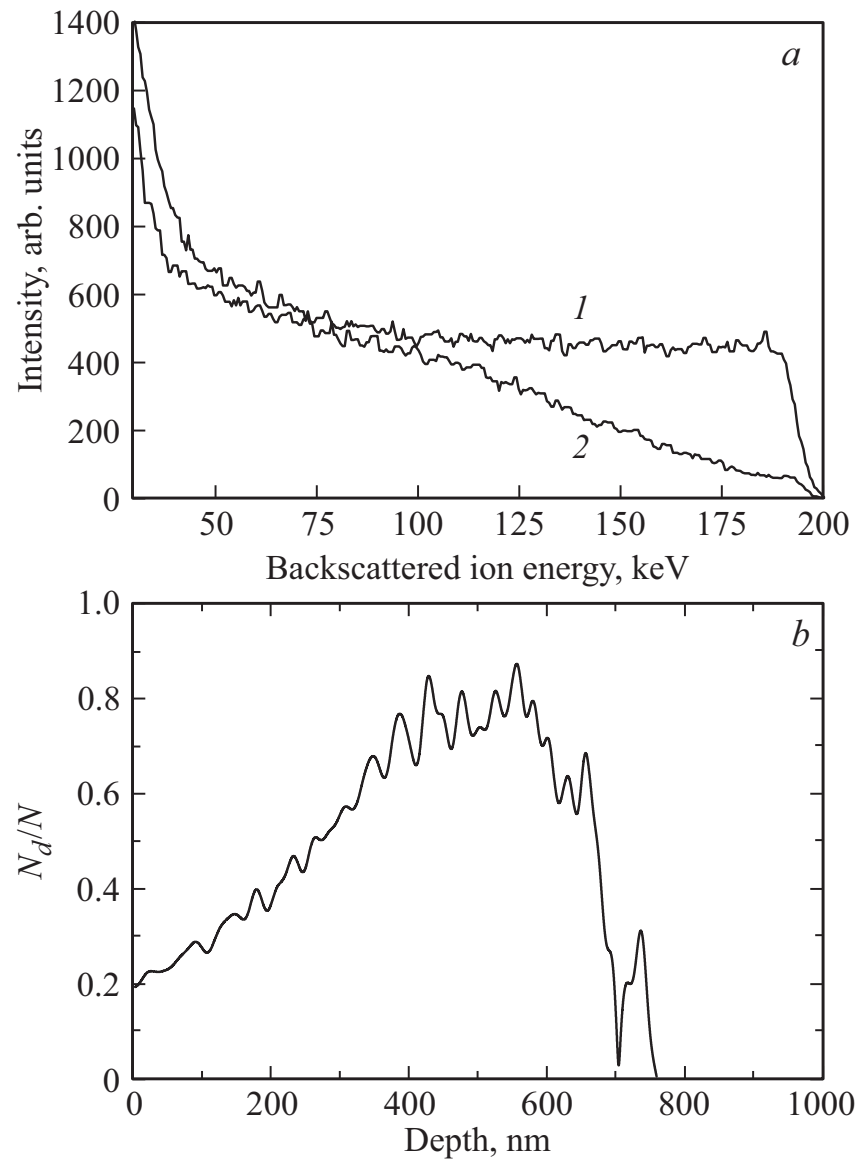

Рис. 1. $a-$ спектры RBS протонов, измеренные в случайном (1) и каналирующем (2) режимах для имплантированного $p$-Cz-Si: Ge образца. $b$ - концентрационные профили точечных дефектов, введенных имплантацией в структуру $\mathrm{Si}: \mathrm{Ge}$.

разрешением 3.5 кэВ регистрировал протоны, рассеянные на угол $170^{\circ}$. Измерение энергетических спектров обратно рассеянных протонов проводилось в режимах каналирования и псевдослучайного направления пучка (далее каналирующий и случайный режимы). Концентрационные профили носителей заряда определялись из вольт-фарадных характеристик (ВФХ) барьера Шоттки $\mathrm{Hg}-\mathrm{Si}$ (ртутный зонд) при комнатной температуре на частоте тестирующего сигнала 1 МГц.

Спектры RBS протонов в образце после имплантации ионов $\mathrm{Ge}$, измеренные в случайном и каналирующем режимах, приведены на рис. $1, a$ (кривые 1 и 2 соответственно). Анализ спектров показывает, что аморфизации имплантированного слоя не происходит: интенсивность случайного сигнала во всем диапазоне измерений выше, чем у каналирующего. Профиль концентрации введенных точечных дефектов рассчитывался исходя из спектра RBS, с помощью процедуры, предложенной в работе [12]. Нормированный на концентрацию атомов в решетке $\mathrm{Si}$ профиль точечных дефектов приведен на рис. 1, $b$. Максимальный уровень радиационных нарушений достигает $80 \%$. Наблюдающийся резкий спад в профиле концентрации введенных дефектов для глубин более 600 нм обусловлен не физическими причинами, а нарастанием погрешности при применении процедуры из работы [12] для используемых зондирующих ионов водорода средних энергий.

Изохронные (в течение 30 мин) отжиги имплантированных образцов проводились при температурах 700 и $900^{\circ} \mathrm{C}$ в хлорсодержащей атмосфере, которая представляла собой поток кислорода, насыщенный парами четыреххлористого углерода с молярной концентрацией $1 \%$. Измерения, проведенные с помощью термозонда, показали, что имплантация ионов германия и последующий отжиг не приводят к образованию в приповерхностной области слоя $n$-типа проводимости, как это наблюдалось для образцов $\mathrm{Si}:(\mathrm{O}, \mathrm{Er}, \mathrm{Ho}, \mathrm{Dy}$, $\mathrm{Yb}$ ) [4-9], а сохраняется дырочный тип проводимости. Измеренные профили дырок после отжигов при 700 и $900^{\circ} \mathrm{C}$ приведены на рис. 2. Концентрационные профили имеют вид кривых с минимумами на глубинах 1.2 и 0.8 мкм при температурах отжига 700 и $900^{\circ} \mathrm{C}$ соответственно и с максимумами на глубинах 1.3-1.4 мкм при обеих температурах отжига. На глубинах более 1.7 мкм концентрация дырок не зависит от температуры отжига и остается на уровне легирования исходной пластины кремния бором. В области минимума концентрация дырок в 2-3 раза меньше уровня легирования, тогда как в области максимума в $\sim 1.8$ раза выше.

Наличие акцепторных центров в отожженных $\mathrm{Si}: \mathrm{Ge}-$ структурах и их поведение в зависимости от условий отжига коренным образом отличаются от ситуации с $\mathrm{Si}:(\mathrm{O}, \mathrm{Er}, \mathrm{Ho}, \mathrm{Dy}, \mathrm{Yb})$ образцами, отожжеными в аналогичных температурно-временны́х режимах. В последнем случае после отжига происходило образование донорных центров, сопровождающееся $p-n$ конверсией типа проводимости имплантированных слоев, а также изменением параметров концентрационных профилей

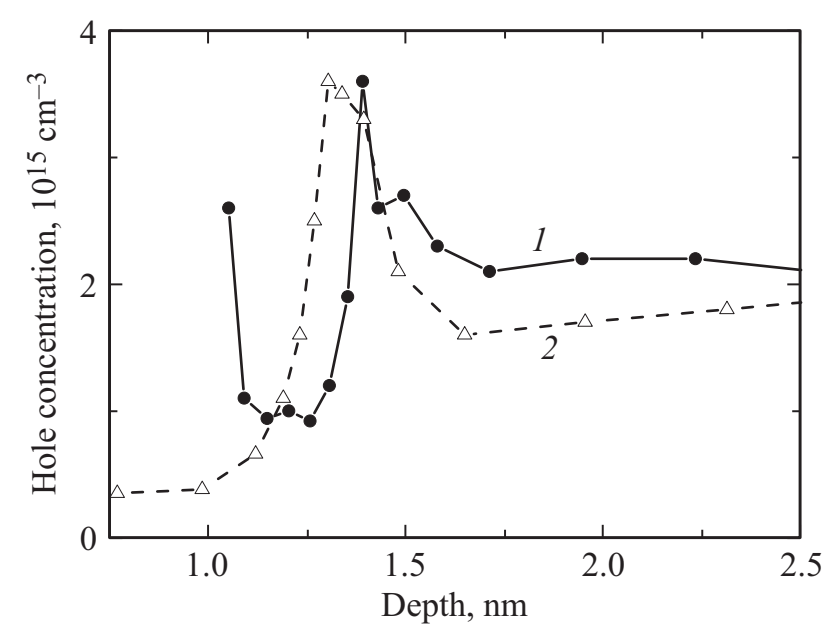

Рис. 2. Концентрационные профили дырок в $p$-Cz-Si образцах после имплантации ионов германия и отжига в течение 0.5 ч в хлорсодержащей атмосфере при разных температурах, ${ }^{\circ} \mathrm{C}$ : 700 (1) и 900 (2). 
образовавшихся донорных центров: с ростом температуры отжига значения максимальных концентраций уменьшаются, а их положение смещается в глубь образца [4-9]. Природа образовавшихся электрически активных центров в $\mathrm{Si}:(\mathrm{O}, \mathrm{Er}, \mathrm{Ho}, \mathrm{Dy}, \mathrm{Yb})$ определялась с помощью измерений эффекта Холла и фотопроводимости (фототермической ионизационной спектроскопии) $[4,6,13]$, а также подтверждено моделированием процесса формирования кислородных термодоноров [8]. Было установлено, что в отожженных $\mathrm{Si}:(\mathrm{O}, \mathrm{Er}, \mathrm{Ho}$, $\mathrm{Dy}, \mathrm{Yb})$ образцах формируются кислородные термодоноры, модифицированные за счет имплантированных примесных Р3 ионов. Это согласуется с известным экспериментальным фактом о эффективном притяжении Р3 элементами атомов кислорода [14]. В формировании образующихся донорных центров значительную роль играют собственные точечные дефекты (в первую очередь кремниевые межузельные атомы), образующиеся во время имплантации и отжига и активно взаимодействующие между собой и примесными атомами. Именно собственные дефекты решетки кремния и приводят к изменению значений концентраций донорных центров и расположения их максимумов при увеличении температуры отжига. Также было показано, что расположение образовавшихся донорных центров практически совпадает с областью, в которой формировалась бо́льшая часть выявленных при электронно-микроскопических исследованиях структурных дефектов, в первую очередь преципитатов кислорода и дислокационных петель [2].

Отсутствие модифицированных кислородных термодоноров в отожженных образцах $\mathrm{Si}: \mathrm{Ge}$ обусловлено экспериментально установленной способностью атомов германия снижать скорость и даже предотвращать образование классических кислородных термодоноров [15]. Следует отметить, что предварительные исследования спектров фотолюминесценции при температуре $10 \mathrm{~K}$ исследуемых в данной работе образцов выявили появление линии на длине волны 1.2 мкм, положение которой не изменяется с температурой отжига. Образование акцепторных центров ранее наблюдалось в имплантированных или облученных быстрыми нейтронами образцах после отжига в исследуемом в данной работе диапазоне температур [16], однако надежной идентификации таких центров не было установлено. Вид концентрационных профилей дырок с минимумом на глубинах $(1.1-1.6) \cdot R_{p}$ и последующим максимумом на глубине $(1.8-1.9) \cdot R_{p}$ может быть обусловлен перераспределением исходной легирующей примеси бора. Как и в случае протонно-стимулированной диффузии [17], примесь бора уходит из области генерации собственных точечных дефектов (СТД) в составе подвижных пар бор-собственный межузельный атом (B-I), образуя минимум на профиле распределения дырок. При выходе из этой области генерации СТД пары B-I распадаются, образуя максимум на профиле распределения дырок.

Таким образом, обнаружено, что имплантация ионов $\mathrm{Ge}^{+}$с энергией $1 \mathrm{MэВ} \mathrm{и} \mathrm{дозой} 2.5 \cdot 10^{14} \mathrm{~cm}^{-2}$ не приводит к аморфизации кремния. Последующие изохронные отжиги в течение 30 мин при $700-900^{\circ} \mathrm{C}$ в хлорсодержащей атмосфере не изменяют $p$-тип проводимости кремния и приводят к образованию профиля дырок с минимумом на глубинах $(1.1-1.6) \cdot R_{p}$ и последующим максимумом на глубине $(1.8-1.9) \cdot R_{p}$. Обнаруженный эффект отличается от результатов, полученных при имплантации ряда других ионов $(\mathrm{O}, \mathrm{Er}$, Ho, Dy и $\mathrm{Yb}$ ), когда после отжигов в аналогичных условиях образуются термодоноры с высокой концентрацией, достаточной для $p-n$ конверсии типа проводимости исходного Si. Наблюдаемый профиль дырок можно объяснить перераспределением исходной легирующей примеси бора - ее уходом из области генерации СТД в имплантированном ионами германия слое и накоплением при выходе из нее.

Ионная имплантация проводилась на оборудовании ЦКП „Диагностика микро- и наноструктур“ (ЯФ ФТИАН РАН).

\section{Список литературы}

[1] L. Pavesi. J. Phys.: Condens. Matter, 15, R1169 (2003).

[2] Н.А. Соболев. ФТП, 10, 23 (2010).

[3] N.A. Sobolev, A.E. Kalyadin, E.I. Shek, K.F. Shtel'makh, V.I. Vdovin, A.K. Gutakovskii, L.I. Fedina. Phys. Status Solidi A, 214, 1700317 (2017).

[4] N.A. Sobolev, O.V. Alexandrov, V.V. Emtsev, M.I. Makovijchuk, A.V. Merkulov, E.O. Parshin, D.S. Poloskin, E.I. Shek. Dif. Def. Data, Solid State Data B, Sol. St. Phenomena, 47-48, 299 (1996).

[5] О.В. Александров, Н.А. Соболев, Е.И. Шек, А.В. Меркулов. ФТП, 30, 876 (1996).

[6] В.В. Емцев, В.В. Емцев (мл.), Д.С. Полоскин, Н.А. Соболев, Е.И. Шек, Й. Михель, Л.С. Кимерлинг. ФТП, 33, 649 (1999).

[7] О.В. Александров, А.О. Захарьин, Н.А. Соболев. ФТП, 36, 134 (2002).

[8] О.В. Александров, А.О. Захарьин, Н.А. Соболев. ФТП, 39, 776 (2005).

[9] Н.А. Соболев, Д.В. Данилов, О.В. Александров, А.С. Лошаченко, В.И. Сахаров, И.Т. Серенков, Е.И. Шек, И.Н. Трапезникова. ФТП, 49, 418 (2015).

[10] В.В. Емцев, Т.В. Машовец. Примеси и точечные дебекты в полупроводниках, под ред. С.М. Рывкина (М., Радио и связь, 1981).

[11] J.F. Ziegler, M.D. Ziegler, J.P. Biersack. Nucl. Instrum. Meth. B, 268, 1818 (2010).

[12] L.C. Feldman, J.W. Mayer, S.T. Picraux. Material analysis by ion channeling, (N.Y., Academic Press, 1982) Chap. 5.

[13] V.V. Emtsev, jr, C.A.J. Ammerlaan, B.A. Andreev, G.A. Oganesyan, D.S. Poloskin, E.I. Shek, N.A. Sobolev. Physica B, 308-310, 350 (2001).

[14] J. Michel, J.L. Benton, R.F. Ferrante, D.C. Jacobson, D.J. Eaglesham, E.A. Fitzgerald, Y.H. Xie, J.M. Poate, L.C. Kimerling. J. Appl. Phys., 70, 2672 (1991).

[15] Can Cui, Deren Yang, Xiangyang Ma, Ming Li, Duanlin Que. Mater. Sci. Semicond. Process., 9, 110 (2006). 
[16] В.В. Емцев, Д.С. Полоскин, Н.А. Соболев, Е.И. Шек. ФТП, 28, 1084 (1994).

[17] О.В. Александров, В.В. Козловский. ФТП, 42, 262 (2008).

Редактор А.Н. Смирнов

\section{Influence of annealing temperature on electrically active centers in silicon implanted by germanium ions}

N.A. Sobolev' ${ }^{1}$, O.V. Aleksandrov' ${ }^{2}$, V.I. Sakharov ${ }^{1}$, I.T. Serenkov' ${ }^{1}$, E.I. Shek ${ }^{1}$, A.E. Kalyadin ${ }^{1}$, E.O. Parshin ${ }^{3}$, N.S. Melesov ${ }^{3}$

${ }^{1}$ loffe Institute, 194021 St. Petersburg, Russia

${ }^{2}$ St. Petersburg State Electrotechnical University „LETl“, 197376 St. Petersburg, Russia

${ }^{3}$ Yaroslavl Branch of the Institute of Physics and Technology, Russian Academy of Sciences, 150007 Yaroslavl, Russia

Abstract It was established that the implantation of $p$-type silicon grown by Czochralski method by germanium ions with $1 \mathrm{MeV}$ energy and $2.5 \cdot 10^{14} \mathrm{~cm}^{-2}$ dose does not lead to amorphization of single crystal silicon. Transformation of electrically active centers takes place during subsequent high temperature annealing. Their concentration and special distribution depend on annealing temperature. Possible factors determining their formation are discussed. 